\title{
DNA replication licensing and cell cycle kinetics of normal and neoplastic breast
}

\author{
A Shetty', M Loddo', T Fanshawe ${ }^{3}$, AT Prevost ${ }^{3}$, R Sainsbury ${ }^{*, 4}$, GH Williams ${ }^{1,2}$ and K Stoeber ${ }^{1,2}$ \\ 'Department of Pathology, University College London, Rockefeller Building, University Street, London WCIE 6JJ, UK; ' ${ }^{2}$ Wolfson Institute for Biomedical \\ Research, University College London, The Cruciform Building, Gower Street, London WCIE 6BT, UK; ${ }^{3}$ Centre for Applied Medical Statistics, Department of \\ Public Health and Primary Care, University of Cambridge, Fonvie Site, Robinson Way, Cambridge CB2 2SR, UK; ${ }^{4}$ Department of Surgery, Royal Free and \\ University College Medical School, University College London, Charles Bell House, 67-73 Riding House Street, London WIW 7EJ, UK
}

\begin{abstract}
Mcm2-7 (MCM) proteins are part of the origin licensing machinery that regulates initiation of DNA replication. Geminin is a licensing repressor and prevents reinitiation of DNA replication during $S-G 2-M$ phase by blocking reloading of $M \mathrm{~cm} 2-7$ at replication origins. Here, we have analysed these replication licensing factors (RLFs) to determine whether the pathway becomes deregulated during mammary carcinogenesis, and have assessed their potential value as prognostic markers. Protein expression profiles were generated for Ki67, Mcm2, geminin, HER-2, ER and PR in a series of reduction mammoplasty $(n=18)$ and breast cancer specimens $(n=120)$, and compared to clinicopathological parameters. A large proportion of epithelial cells of the terminal duct lobular unit reside in a primed 'replication licensed' but not proliferating state. This state is characterised by Mcm2 expression and absence of Ki67 and the S/G2/M marker geminin. In breast cancers, increasing tumour grade is associated with increased Ki67, Mcm2 and geminin expression. The $\mathrm{Mcm} 2 / \mathrm{Ki} 67$ ratio decreases through the grades, indicating a shift from a predominantly licensed state to an actively proliferating state. This shift is associated with an increase in the geminin/Ki67 ratio, signifying a shortening of GI phase in breast cancer cells. Ki67, Mcm2 and the Mcm2/Ki67 ratio are statistically significantly associated with the Nottingham Prognostic Index (NPI), but geminin and the geminin/Ki67 ratio are not. Ki67, $\mathrm{Mcm} 2$ and $\mathrm{Mcm} 2 / K i 67$ are highly correlated with one another, with $\mathrm{Mcm} 2 \mathrm{being}$ the single most important predictor of NPI score $(P<0.00 \mathrm{I})$. However, only I $2 \%$ of variation in NPI is explained by $\mathrm{Mcm} 2$, as the labelling index for this marker is approaching 100\% for many of the high-grade tumours. The origin licensing phenotypes of normal breast and breast cancers therefore relate to their cellular differentiation status, and high-level MCM expression in more poorly differentiated tumours severely constrains their use as prognostic markers in breast cancer.

British Journal of Cancer (2005) 93, 1295-1300. doi:I0.1038/sj.bjc.6602829 www.bjcancer.com

Published online 8 November 2005

(c) 2005 Cancer Research UK
\end{abstract}

Keywords: Ki67; Mcm2; MCM; geminin; DNA replication licensing; breast cancer

With one million new cases in the world each year, breast cancer is the most common malignancy in women and comprises $18 \%$ of all female cancers. In the UK, breast cancer accounts for more than 14000 deaths each year and the incidence is increasing with a prevalence of nearly $2 \%$ (McPherson et al, 2000). In spite of being one of the most aggressive cancers in women worldwide, there are encouraging signs that improvement in the mortality rate may be possible through earlier diagnosis and improved therapeutic interventions (Mori et al, 2002). Breast cancer is a complex disease due to its morphological and biological heterogeneity, its tendency to acquire chemo-resistance and the existence of several molecular mechanisms underlying its pathogenesis (Mori et al, 2002). Half of the women who receive loco-regional treatment for breast cancer will never relapse, whereas the other half will eventually die from metastatic disease (Bundred, 2001). It is therefore imperative to distinguish clearly between these two groups of patients for optimal clinical management. Unfortunately,

*Correspondence: R Sainsbury; E-mail: r.sainsbury@ucl.ac.uk Received 21 February 2005; revised I August 2005; accepted 23 August 2005; published online 8 November 2005 prognostic markers for breast cancer are at present limited. The most widely used prognostic indicator is the Nottingham Prognostic Index (NPI), which combines the traditional and most important independent predictors of outcome including tumour size, histological grade and lymph node stage (Rampaul et al, 2001).

The initiation of DNA synthesis is a final and critical step in growth control and is therefore of importance in carcinogenesis. Initiation of eukaryotic DNA replication is dependent on the assembly onto chromatin of prereplicative complexes (pre-RCs) containing the origin recognition complex (ORC), Cdc6, Cdt1 and Mcm 2-7 proteins (Bell and Dutta, 2002), thereby rendering origins licensed for one round of DNA replication during $S$ phase (Mendez and Stillman, 2000; Blow and Hodgson, 2002; Dimitrova et al, 2002). Pre-RCs are activated by cyclin dependent kinases (CDK) and the Cdc7/ASK kinase, leading to recruitment of elongation factors, Cdc45, DNA polymerases and RPA to origins (Masai and Arai, 2002; Nishitani and Lygerou, 2002). The recruitment of these factors results in unwinding of the DNA helix and initiation of DNA synthesis (Lei and Tye, 2001). Replication initiation is tightly coupled to removal of the license, thus preventing re-licensing after origin firing. This step is critical, 
as origins must fire once and only once in each cell cycle to ensure genomic stability. To avoid re-licensing, mammalian cells have adopted a number of mechanisms. These include the inactivation of licensing factors during S-G2-M phase, a process controlled by CDK activity, regulated proteolysis and changes in gene expression. A further important mechanism is the repression of origin licensing by geminin (Nishitani and Lygerou, 2002). This repressor acts by competitively binding to Cdt1, thereby blocking Mcm 2-7 re-loading onto chromatin (McGarry and Kirschner, 1998; Wohlschlegel et al, 2000; Quinn et al, 2001; Tada et al, 2001). Using membrane elution, we have demonstrated for human cells that geminin expression is restricted to the S, G2 and M phases of the cell cycle, in keeping with its function of preventing re-replication (Eward et al, 2004; Wharton et al, 2004).

The constituents of the pre-RC can be regarded as relay stations coupling growth regulatory pathways with DNA replication, thereby serving as novel biomarkers of growth (Williams and Stoeber, 1999). We have shown that repression of origin licensing is a ubiquitous route by which the proliferative capacity of metazoan cells is lowered during exit from the mitotic cell cycle. Withdrawal from cycle into quiescent $(\mathrm{G} 0)$, differentiated or senescent states is coupled to downregulation of Cdc6 and MCM proteins. We have also demonstrated in a range of different tumour types that deregulation of $\mathrm{Mcm} 2-7$ is an early event in tumourigenesis, and have exploited these novel biomarkers of growth in primary diagnosis, surveillance and prognosis (Williams et al, 1998, 2004; Stoeber et al, 1999, 2001, 2002; Meng et al, 2001; Wharton et al, 2004). These studies have shown that the superior sensitivity of the MCM proteins over the standard proliferation marker Ki67 resides in the fact that $\mathrm{Mcm} 2-7$ identify not only cycling cells, but also noncycling cells with proliferative potential (Stoeber et al, 2001). Interestingly, this particular replication phenotype (Ki67 negative but MCM positive) is exhibited by premenopausal breast (Stoeber et al, 2001) and primary oocytes (Eward et al, 2004), resting tissues that retain proliferative capacity and that can respond rapidly to growth stimuli.

Here we have investigated regulation of $\mathrm{Mcm} 2$ and geminin in normal premenopausal breast to more precisely define the cell cycle kinetics of this unusual tissue type, which undergoes rapid periodic expansion. We have also analysed deregulation of the replication licensing pathway during mammary tumourigenesis. Expression of $\mathrm{Mcm} 2$ and geminin has been compared with receptor status (HER-2, ER, PR) and the standard proliferation marker Ki67 to investigate coupling between DNA replication licensing and differentiation. Expression profiles of these new molecular markers have been compared to clinicopathological parameters to assess their prognostic value.

\section{MATERIALS AND METHODS}

\section{Clinical specimens}

Patients who had surgery for invasive breast cancer were identified by a search of the histopathology records at University College London, UK. Archival formalin-fixed, paraffin-embedded breast tissue was retrieved from the archives of the Department of Pathology for 120 cases of invasive breast cancer, which included all three histological grades $(1-3)$ calculated according to the Nottingham modification of the Bloom and Richardson method (Elston and Ellis, 2002). Histological reports and slides were available for all cases. These included 93 invasive ductal carcinomas, 20 lobular, four mucinous and three of mixed type. The parameters studied were histological grade, tumour size, tumour type, lymph node status, lymphovascular invasion (LVI), age and NPI. We also studied randomly selected cases of normal breast tissue from 18 women, 17 of whom had undergone reduction mammoplasty and one a prophylactic mastectomy for
BRCA1. Local research ethics committee approval was obtained from the joint UCL/UCLH Committees on the Ethics of Human Research.

\section{Antibodies}

Mouse anti-human monoclonal $\mathrm{Mcm} 2$ antibody (clone 46) was obtained from BD Transduction Laboratories ${ }^{\mathrm{TM}}$ (Lexington, KY, USA). Mouse anti-human monoclonal Ki67 (clone Mib-1), mouse monoclonal oestrogen receptor- $\alpha$ (clone 1D5) and mouse monoclonal progesterone receptor (clone PgR 636) antibodies were obtained from DAKO (Glostrup, Denmark). Affinity-purified rabbit polyclonal antibody G95 was generated against human geminin as described (Wharton et al, 2004).

\section{Immunohistochemistry}

Sections $(3 \mu \mathrm{m})$ of formalin-fixed, paraffin-embedded tissues were cut onto DAKO TechMate ${ }^{\mathrm{TM}}$ S2024 charged slides, baked in a $60^{\circ} \mathrm{C}$ oven overnight to maximise section adhesion, dewaxed in xylene, and rehydrated through a series of alcohol to water. For antigen retrieval, tissues were pressure-cooked for $2 \mathrm{~min}$ in $0.1 \mathrm{M}$ citrate buffer at $\mathrm{pH}$ 6.0. For ER, PR, Ki67, $\mathrm{Mcm} 2$ and geminin detection, automatic immunostaining was performed on a DAKO TechMate ${ }^{\mathrm{TM}}$ 500 as described (Dogan et al, 2000). Endogenous peroxidase activity was quenched by incubating the sections with peroxidase blocking solution (DAKO, S2023) for $10 \mathrm{~min}$. Sections were then washed twice using Tris-buffered saline containing $0.1 \%$ Tween-20 (SIGMA, St Louis, USA) for this and subsequent washes. Slides were incubated with primary antibodies for $1 \mathrm{~h}$ at room temperature using the following concentrations: ER (1/100), PR (1/50), Ki67 (1/50), Mcm2 (1/1000), geminin (G95) (1/1000). After washing, antigen-bound primary antibodies were detected with a labelled streptavidin biotin detection system (DAKO ChemMate ${ }^{\mathrm{TM}}$ K5001). Slides were incubated with biotinylated secondary antibody (Ab2) for $30 \mathrm{~min}$. After washing sections were incubated with streptavidin horseradish peroxidase for $30 \mathrm{~min}$. After washing, the immunostain was developed applying 3,3-diaminobenzidine tetrahydrochloride (DAB) for $7 \mathrm{~min}$. HER-2 immunostaining was performed using the DAKO HercepTest ${ }^{\mathrm{TM}}$ (DAKO K5205), according to the manufacturer's instructions. Slides were counter-stained with Mayer's haematoxylin, differentiated in $1 \%$ acid alcohol, dehydrated and cleared in xylene. Coverslips were applied with Leica CV Mount (Leica, Nussloch, Germany). Primary antibodies were omitted in negative controls and, in addition, appropriate tissue sections were used as positive and negative controls.

\section{Protein expression profile analysis}

Slides were examined and 3-5 fields were captured with an Olympus BX51 microscope/CCD camera setup using ANAlysis software (SIS, Münster, Germany). Captured images were printed for quantitative analysis, and the labelling index (LI) for each marker was calculated as the percentage of cells stained positive. Cells were identified as positive if there was any nuclear staining present and any stromal or inflammatory cells on the field were excluded. A median of 400 cells was counted per slide. For evaluation of HER-2 protein overexpression, membrane staining was assessed following the criteria recommended by DAKO. Slides were examined by three independent investigators (GHW, ML and AS). GHW is a consultant histopathologist and re-examined all cases analysed by ML and AS. This assessment of interobserver variability showed high concordance.

\section{Statistical analysis}

Different statistical techniques were used to compare the expression of markers to grade, lymph node metastasis, tumour size, NPI, 
and LVI. The Jonkheere-Terpstra test was used to examine whether there was any association between marker expression and grade. This is a nonparametric test, which takes into account the ordering of the categories of grade. A logistic regression model was used to analyse the relationship between marker expression and lymph node metastasis. Spearman's rank correlation coefficient was used to examine the association between marker expression and tumour size. Linear regression was used to model the relationship between marker expression and NPI. A MannWhitney test was used to examine the association between marker expression and LVI.

\section{RESULTS}

DNA replication licensing and cell cycle kinetics of normal resting breast tissue

We first studied expression of $\mathrm{Mcm} 2$, geminin, Ki67, and the ER and PR hormone receptors in a series of normal breast specimens $(n=18)$. As reported by ourselves and others (Stoeber et al, 2001; Gonzalez et al, 2003), high-level Mcm2 expression was observed in epithelial cells of the terminal duct lobular unit (TDLU) in normal resting premenopausal breast (Table 1, Figure 1A and B). Whereas the level of $\mathrm{Mcm} 2$ expression was high, Ki67 was expressed at low levels (median Mcm2: 35.32\% (range 4.9-98.43) compared to Ki67: $2.14 \%$ (range $0.22-35.32$ )). Geminin is present in only a minority of cells in premenopausal breast (median: $0.76 \%$ (range $0-13.87$ )). These data are in keeping with a high proportion of mammary epithelial cells residing in a licensed MCM expressing but nonproliferating state (Stoeber et al, 2001).

\section{DNA replication licensing and cell cycle kinetics of breast cancer}

Next we asked whether DNA replication licensing is coupled to cellular differentiation in breast cancer. To address this question, we compared Ki67, Mcm2 and geminin expression with ER and PR status in an invasive breast carcinoma series $(n=120$, Table 2$)$. Expression profiles of replication licensing factors (RLFs) and differentiation markers were compared with tumour size, grade, lymph node status, vascular invasion and NPI. Median labelling indices for each protein are shown in Table 1 and Figure 2, and representative immunostained tissue sections are illustrated in Figure 3. As part of the analysis, $\mathrm{Mcm} 2 / \mathrm{Ki} 67$ and geminin/Ki67 ratios were also calculated for each tumour. Both Ki67 and $\mathrm{Mcm} 2$ are expressed throughout all four phases of the mitotic cell cycle (G1, S, G2 and M). Mcm 2-7 protein expression also identifies noncycling cells with proliferative potential (Stoeber et al, 2001; Eward et al, 2004; Wharton et al, 2004). The $\mathrm{Mcm} 2 / \mathrm{Ki} 67$ ratio therefore defines the proportion of cells that are licensed to proliferate. Consequently, the higher the $\mathrm{Mcm} 2 / \mathrm{Ki} 67$ ratio, the greater the proportion of cells that reside in a licensed noncycling state (Eward et al, 2004; Wharton et al, 2004).

Increasing grade of tumour was associated with significantly increased expression of $\mathrm{Ki} 67, \mathrm{Mcm} 2$ and geminin, and lower expression of the differentiation markers ER and PR (JonkheereTerpstra test, $P<0.001$ in each case; Table 1 and Figure 2). The decrease in the $\mathrm{Mcm} 2 / \mathrm{Ki} 67$ ratios with increasing grade reflects a shift in the tumour cell population from a predominantly nonproliferating licensed state in differentiated tumours to an actively cycling state in poorly differentiated tumours (median grade 1: 4.13 , grade $2: 2.56$, grade $3: 1.85 ; P<0.001$ ). As in the case of well-differentiated tumours, normal breast has a similarly high $\mathrm{Mcm} 2 / \mathrm{Ki} 67$ ratio (median: 11.16) indicative of a licensed nonproliferating state. The shift from the latter state to the proliferating state with increasing tumour grade is also reflected by the increase in geminin expression, indicating that cells are

Table I Marker expression (median percentage of cells positive) across different tumour grades

\begin{tabular}{lcccc}
\hline Marker & Normal tissue & Grade I & Grade 2 & Grade 3 \\
\hline Ki67 & 2.14 & 10.26 & 17.11 & 43.66 \\
Mcm2 & 35.32 & 55.17 & 70.16 & 96.91 \\
Geminin & 0.76 & 2.00 & 6.48 & 17.14 \\
ER & 22.13 & 100 & 100 & 13.88 \\
PR & 19.60 & 100 & 98.11 & 0 \\
Mcm2/Ki67 & $11.16^{\mathrm{a}}$ & 4.13 & 2.56 & 1.85 \\
Gem/Ki67 & $0.46^{\mathrm{a}}$ & 0.29 & 0.32 & 0.36 \\
\hline
\end{tabular}

${ }^{a}$ Figures unreliable as Ki67 staining \% is low.

A
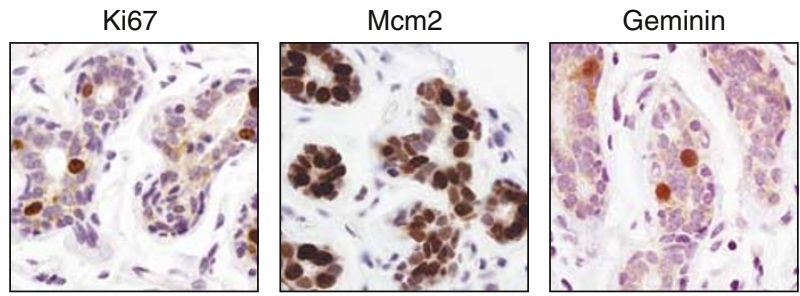

B

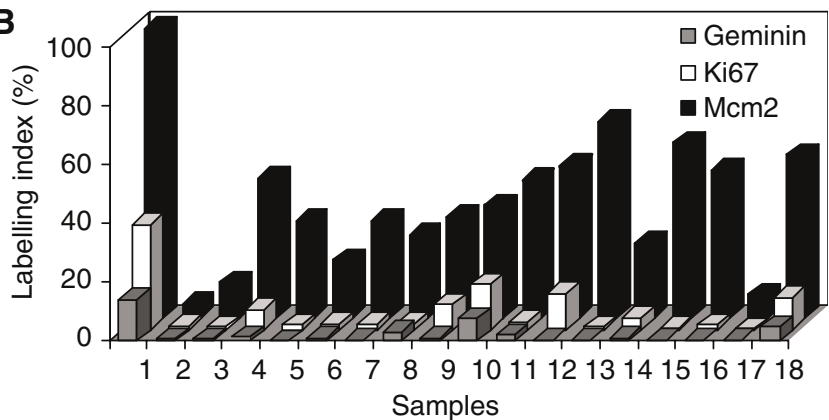

Figure I (A) Photomicrographs of paraffin-embedded tissue sections of normal premenopausal breast immunohistochemically stained with antibodies against Ki67, Mcm2 and geminin (original magnification, $\times 400$ ). A high proportion of epithelial cells of the terminal duct lobular unit express Mcm2, a subpopulation Ki67 and only a minority geminin. The higher labelling index for $\mathrm{Mcm} 2$ compared to Ki67 reflects an additional replication licensed but nonproliferating growth fraction, identified by $\mathrm{Mcm} 2$ but not the standard proliferation marker Ki67. (B) Ki67, Mcm2 and geminin labelling indices for individual cases of normal premenopausal breast. Case I showing high levels of $\mathrm{Ki67}, \mathrm{Mcm} 2$ and geminin expression is a patient who had a prophylactic mastectomy for BRCAI. All other cases of reduction mammoplasty show higher expression of $\mathrm{Mcm} 2$ compared to Ki67 and geminin.

engaging in DNA synthesis and progressing through S-G2-M phase (median grade 1: $2.00 \%$, grade $2: 6.48 \%$, grade $3: 17.14 \%$; $P<0.001)$. Higher tumour grade is also associated with an increase in the geminin/Ki67 ratio, signifying a shortening of G1 phase for the more malignant phenotype (grade 1: 0.29 s grade 3: 0.36; $P=0.07)$ and an increase in HER-2 expression $(P=0.05)$. Interestingly, higher expression levels of geminin were observed in invasive ductal carcinoma compared to lobular carcinoma (median: 12.41 vs $7.14 \% ; P<0.02$ ).

A logistic regression model shows that none of the markers including Ki67, Mcm2, geminin, ER, PR, HER-2, nor the $\mathrm{Mcm} 2 /$ Ki67 or geminin/Ki67 ratios, have any statistically significant association with lymph node metastasis (Table 3). Moreover, the low values of Spearman's correlation coefficient indicate that there is no association between tumour size and any of these markers (Table 4). The results of the Mann-Whitney test indicate that 
Table 2 Clinicopathological details of invasive breast cancer series

\begin{tabular}{|c|c|}
\hline Clinicopathological feature & Frequency \\
\hline \multicolumn{2}{|l|}{ Age } \\
\hline$<40$ & 12 \\
\hline $40-59$ & 54 \\
\hline$>60$ & 54 \\
\hline \multicolumn{2}{|l|}{ Size $(m m)$} \\
\hline$<11$ & 12 \\
\hline $11-20$ & 36 \\
\hline $21-30$ & 35 \\
\hline $31-40$ & 17 \\
\hline$>40$ & 16 \\
\hline Unknown & 4 \\
\hline \multicolumn{2}{|l|}{ Lymph node stage } \\
\hline No & 63 \\
\hline Yes & 49 \\
\hline Unknown & 8 \\
\hline \multicolumn{2}{|l|}{ Grade } \\
\hline I & 12 \\
\hline 2 & 53 \\
\hline 3 & 55 \\
\hline \multicolumn{2}{|l|}{ NPI score } \\
\hline$<3.4$ & 22 \\
\hline $3.4-5.4$ & 62 \\
\hline$>5.4$ & 28 \\
\hline Unknown & 8 \\
\hline \multicolumn{2}{|l|}{ Lymphovascular invasion } \\
\hline Absent & 69 \\
\hline Present & 45 \\
\hline Unknown & 6 \\
\hline \multicolumn{2}{|l|}{ Tumour type } \\
\hline Invasive ductal & 93 \\
\hline Lobular & 20 \\
\hline Mucinous & 4 \\
\hline Mixed & 3 \\
\hline
\end{tabular}

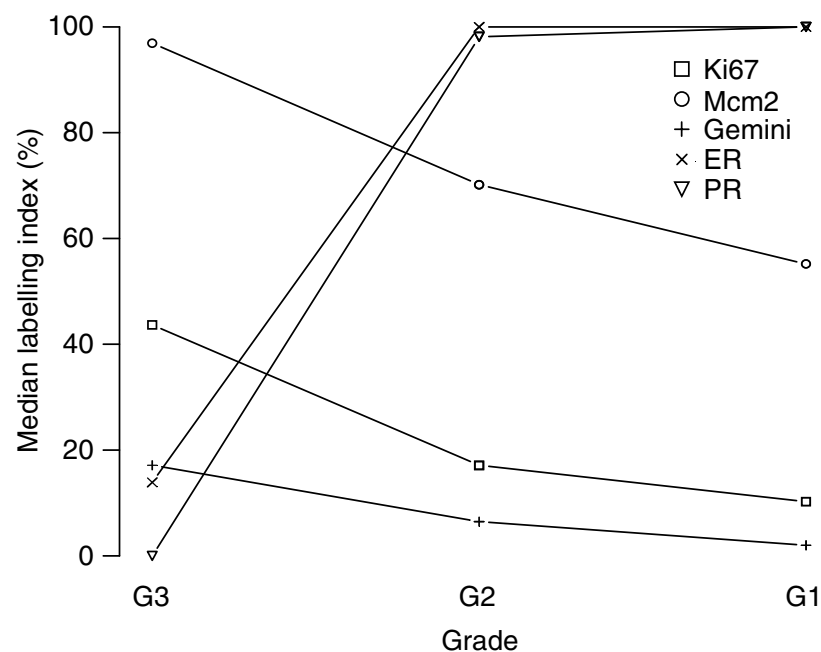

Figure 2 Ki67, Mcm2, geminin, ER and PR labelling indices (median percentage of cells stained positive) depicted across breast cancer grades $\mathrm{I}-3$. Increasing differentiation (from grade 3 to grade I) is associated with decreasing Ki67, Mcm2 and geminin expression and increasing ER and PR labelling indices.

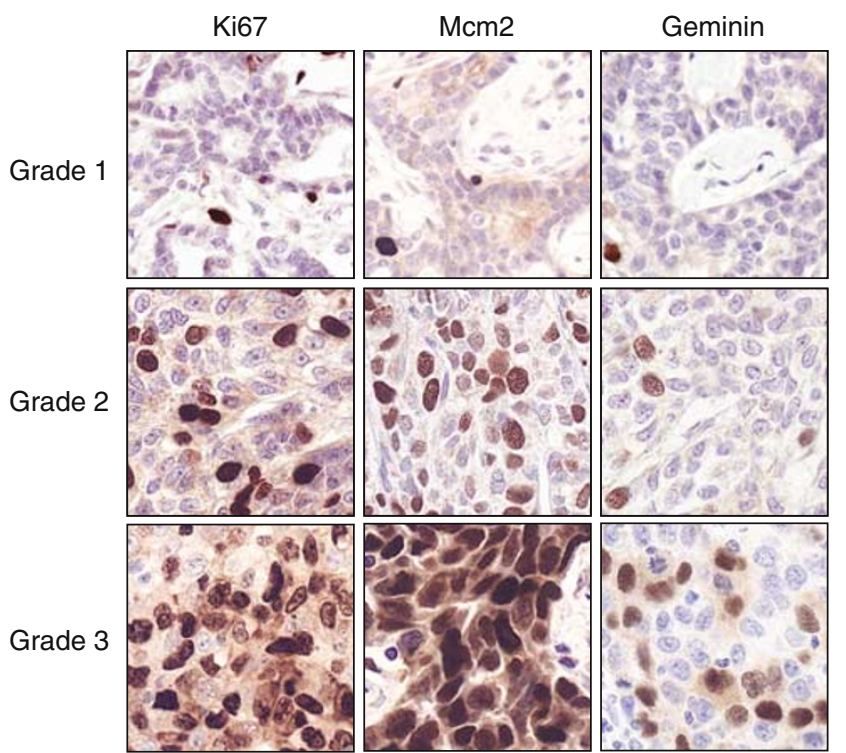

Figure 3 Photomicrographs of paraffin-embedded tissue sections of breast cancer grades I-3 immunohistochemically stained with antibodies against Ki67, $\mathrm{Mcm} 2$ and geminin (original magnification, $\times 400$ ). Increasing tumour grade is associated with increasing Ki67, $\mathrm{Mcm} 2$ and geminin expression. Note that $\mathrm{Mcm} 2$ expression is approaching 100\% in grade 3 cancers.

Table 3 Relationship between median marker expression and lymph node metastasis

\begin{tabular}{lcc}
\hline & \multicolumn{2}{c}{ Lymph node metastasis } \\
\cline { 2 - 3 } Marker & No & Yes \\
\hline Ki67 & 32.42 & 36.35 \\
Mcm2 & 68.74 & 75.01 \\
Geminin & 11.52 & 13.10 \\
ER & 74.75 & 62.59 \\
PR & 60.40 & 50.45 \\
Mcm2/Ki67 & 4.15 & 3.23 \\
Gem/Ki67 & 0.43 & 0.41 \\
\hline
\end{tabular}

Table 4 Correlation between markers and tumour size using Spearman's correlation coefficient

\begin{tabular}{lc}
\hline Marker & Correlation \\
\hline Ki67 & 0.10 \\
Mcm2 & 0.11 \\
Geminin & 0.09 \\
ER & -0.03 \\
PR & -0.02 \\
Mcm2/Ki67 & -0.01 \\
Gem/Ki67 & -0.01 \\
\hline
\end{tabular}

presence of LVI is associated with decreased expression of ER $(P=0.02)$ and PR $(P=0.05)$ but no association with the other markers.

Linear regression models indicate that $\mathrm{Ki} 67, \mathrm{Mcm} 2$ and the $\mathrm{Mcm} 2 / \mathrm{Ki} 67$ ratio are statistically significantly associated with the surrogate outcome measure NPI, but that this association does not apply to geminin or the geminin/Ki67 ratio. The Ki67 and $\mathrm{Mcm} 2$ labelling indices and the $\mathrm{Mcm} 2 / \mathrm{Ki} 67$ ratio are 
highly correlated with one another, with $\mathrm{Mcm} 2$ being the single most important predictor of NPI score $(P<0.001)$. Importantly, only $12 \%$ in the variation of NPI is explained by this marker (the value of $R^{2}$ from the linear regression model equal to the square of Pearson's correlation coefficient between NPI and $\mathrm{Mcm} 2$ ), a consequence of the very high levels of $\mathrm{Mcm} 2$ expression in higher-grade tumours (median grade 3: 96.91\%; Table 1; Figure 2).

\section{DISCUSSION}

We and others have demonstrated that repression of origin licensing is a powerful downstream mechanism by which metazoan cells lower proliferative capacity (Yoshida et al, 1982; Stoeber et al, 2001; Blow and Hodgson, 2002; Eward et al, 2004). Withdrawal of cells from the mitotic cell cycle into quiescent (G0), terminally differentiated or senescent 'out-of-cycle' states is coupled to downregulation of $\mathrm{Mcm} 2-7$ and the origin licensing repressor geminin (Stoeber et al, 2001; Eward et al, 2004; Wharton et al, 2004). Expression profiling of these RLFs in normal premenopausal breast revealed an unusual replication phenotype. Although the growth fraction identified by the standard proliferation marker Ki67 is small, a large number of mammary epithelial cells within the TDLU express $\mathrm{Mcm} 2$, indicating that a large number of cells appear to be licensed and therefore 'in-cycle'. Failure of these licensed cells to progress through the cell cycle is confirmed in this study through their failure to express the S-G2 $\mathrm{M}$ marker geminin. We have previously reported that during pregnancy the proportion of MCM-expressing lobular cells increases to greater $95 \%$, coinciding with cell expansion and also including the myoepithelial cell population. This was followed by dramatic downregulation of the MCM licensing factors as cells entered the terminally differentiated lactating phenotype (Stoeber et al, 2001). It thus appears that persistence of $\mathrm{Mcm} 2-7$ expression in nonproliferating breast may be an evolutionary adaptation allowing a rapid response to pregnancy, and it remains to be determined whether this primed state may predispose the breast to genotoxic insult and facilitate the transition to uncontrolled cell proliferation. In this context it is noteworthy that the prophylactic mastectomy specimen for BRCA1 showed higher levels of Mcm2 expression than the reduction mammoplasty specimens (Figure 1B, case 1).

Our analysis of the DNA replication licensing pathway in breast cancer has revealed that MCM expression is coupled to the differentiation status of tumours. The hierarchical stem cell model of tumour growth proposes that neoplasms represent stem cell systems in which a minority of cells has the proliferative capacity to maintain the tumour, whereas the majority demonstrate features of differentiation and have limited proliferative potential (Reya et al, 2001; Clarke et al, 2003; Dontu et al, 2003). We have demonstrated that loss of proliferative capacity during early stages of differentiation is linked to downregulation of Cdc6, Cdt1, geminin and Ki67. In contrast, downregulation of $\mathrm{Mcm} 2-7$ is a late event when cells enter the terminally differentiated state (Eward et al, 2004). Thus, combinatorial analysis of RLFs and Ki67 allows identification of three distinct replication phenotypes: proliferating cells (Cdc6, Cdt1, Mcm2-7, geminin and Ki67 positive), differentiating cells ( $\mathrm{Mcm} 2-7$ positive; Cdc6, Cdt1, geminin and Ki67 negative) and terminally differentiated cells (Cdc6, Cdt1, Mcm2-7, geminin and Ki67 negative). The particular replication phenotype observed in breast cancer is entirely in keeping with the hierarchical stem cell model of tumour growth, the uncoupling of $\mathrm{Mcm} 2$ expression with geminin and Ki67 expression increasing with a higher degree of differentiation.

We have recently shown that geminin expression provides an estimate of the S-G2-M growth fraction in dynamic cell populations, and that the geminin/Ki67 ratio defines the relative length of G1 (Eward et al, 2004). Proliferating cells with a short G1 phase will approximate to a geminin/Ki67 ratio of $\sim 1$, whereas cells with a prolonged G1 will approximate to a ratio of $\sim 0$ (Wharton et al, 2004). Interestingly, we observed a nonsignificant trend in the geminin/Ki67 ratio between grade 1, grade 2 and grade 3 tumours, with increasing values signifying an accelerated G1 phase in the more poorly differentiated tumours (Table 1). The lower levels of geminin expression in lobular $v s$ ductal carcinoma suggest a higher rate of cell cycle progression in tumours of the latter type.

We have previously reported that the replication licensing pathway is deregulated early in epithelial carcinogenesis, and that the increased growth fraction detected by $\mathrm{Mcm} 2-7$ antibodies compared to Ki67 antibodies can be exploited for cancer detection and surveillance (Williams et al, 1998; Freeman et al, 1999; Stoeber et al, 1999, 2002; Wharton et al, 2001; Going et al, 2002). We and others have also shown that MCM proteins can provide prognostic information in a range of epithelial neoplasms including prostate, kidney and bladder (Meng et al, 2001; Rodins et al, 2002; Kruger et al, 2003; Dudderidge et al, 2005). Recently, (Gonzalez et al (2003) have reported that $\mathrm{Mcm} 2$ is a potentially useful and strong independent prognostic factor in breast cancer. In keeping with our study, the authors showed that the Mcm2 LI has a positive association with histological grade and NPI, but not lymph node stage or LVI. They also noted that the $\mathrm{Mcm} 2 \mathrm{LI}$ is a superior prognostic marker compared to the Ki67 LI. These findings are confirmed in our study in which we identified $\mathrm{Mcm} 2$ as the single most important predictor of the surrogate outcome measure NPI. However, we noted that only $12 \%$ in the variation of the NPI is explained by this marker, a consequence of $\mathrm{Mcm} 2$ expression reaching saturation levels in high-grade tumours. The small value of $12 \%$ suggests that, although there is a statistically significant positive association between $\mathrm{Mcm} 2$ and NPI, there is considerable variability in NPI that cannot be ascribed to expression of $\mathrm{Mcm} 2$ and so the data argue that the usefulness of $\mathrm{Mcm} 2$ as a surrogate measure for NPI is limited. This major constraint in the clinical utility of $\mathrm{Mcm} 2$ as a prognostic marker in breast cancer is also reflected in the fact that Gonzalez et al found the Mcm2 LI not superior to the NPI, the present gold standard prognostic indicator. We have previously demonstrated that the $\mathrm{Mcm} 2-7$ subunits of the hexameric MCM complex show identical cell cycle regulation and are downregulated with similar kinetics during withdrawal from the proliferative cell cycle (Stoeber et al, 2001). Thus, our data suggest that $\mathrm{Mcm} 2-7$ proteins are severely constrained as prognostic markers in breast cancer. Interestingly, we have noted in a separate study that downregulation of $\mathrm{Mcm} 2$ and geminin is linked to hormonal blockade and clinical response, suggesting that although these biomarkers appear to be of limited value for prognostication, they may have potential as predictors of therapeutic response in breast cancer (Shetty et al, unpublished data).

In summary, our investigation of the DNA replication licensing pathway has provided new insights into the cell cycle kinetics of normal and neoplastic breast, findings also of importance for potential therapeutic interventions targeting the DNA replication licensing machinery (Shreeram et al, 2002; Shreeram and Blow, 2003; Yoshida et al, 2004). Our study has shown that although MCM proteins provide prognostic information in breast cancer, these markers are likely to be weak predictors of outcome due to their high-level expression in poorly differentiated tumours.

\section{ACKNOWLEDGEMENTS}

This work has been funded by Cancer Research UK Programme Grant C428/A2281. 


\section{REFERENCES}

Bell SP, Dutta A (2002) DNA replication in eukaryotic cells. Annu Rev Biochem 71: $333 \mathrm{~N}-374 \mathrm{~N}$

Blow JJ, Hodgson B (2002) Replication licensing - defining the proliferative state? Trends Cell Biol 12: $72-78$

Bundred NJ (2001) Prognostic and predictive factors in breast cancer. Cancer Treat Rev 27: $137-142$

Clarke RB, Anderson E, Howell A, Potten CS (2003) Regulation of human breast epithelial stem cells. Cell Prolif 36(Suppl 1): 45-58

Dimitrova DS, Prokhorova TA, Blow JJ, Todorov IT, Gilbert DM (2002) Mammalian nuclei become licensed for DNA replication during late telophase. J Cell Sci 115: 51-59

Dogan A, Bagdi E, Munson P, Isaacson PG (2000) CD10 and BCL-6 expression in paraffin sections of normal lymphoid tissue and B-cell lymphomas. Am J Surg Pathol 24: 846-852

Dontu G, Al Hajj M, Abdallah WM, Clarke MF, Wicha MS (2003) Stem cells in normal breast development and breast cancer. Cell Prolif 36(Suppl 1): $59-72$

Dudderidge TJ, Stoeber K, Loddo M, Atkinson G, Fanshawe T, Griffiths DF, Williams GH. (2005) Mcm2 Geminin and Ki67 define proliferative state and are prognostic markers in renal cell carcinoma. Clin Cancer Res 11: $2510-2517$

Elston CW, Ellis IO (2002) Pathological prognostic factors in breast cancer. I. The value of histological grade in breast cancer: experience from a large study with long-term follow-up. C. W. Elston \& I. O. Ellis. Histopathology 1991; 19; 403-410. Histopathology 41: 151

Eward KL, Obermann EC, Shreeram S, Loddo M, Fanshawe T, Williams C, Jung HI, Prevost AT, Blow JJ, Stoeber K, Williams GH (2004) DNA replication licensing in somatic and germ cells. J Cell Sci 117: 5875-5886

Freeman A, Morris LS, Mills AD, Stoeber K, Laskey RA, Williams GH, Coleman N (1999) Minichromosome maintenance proteins as biological markers of dysplasia and malignancy. Clin Cancer Res 5: $2121-2132$

Going JJ, Keith WN, Neilson L, Stoeber K, Stuart RC, Williams GH (2002) Aberrant expression of minichromosome maintenance proteins 2, 5 and Ki-67 in dysplastic squamous oesophageal epithelium and Barrett's mucosa. Gut 50: $373-377$

Gonzalez MA, Pinder SE, Callagy G, Vowler SL, Morris LS, Bird K, Bell JA, Laskey RA, Coleman N (2003) Minichromosome maintenance protein 2 is a strong independent prognostic marker in breast cancer. J Clin Oncol 21: $4306-4313$

Kruger S, Thorns C, Stocker W, Muller-Kunert E, Bohle A, Feller AC (2003) Prognostic value of MCM2 immunoreactivity in stage T1 transitional cell carcinoma of the bladder. Eur Urol 43: 138-145

Lei M, Tye BK (2001) Initiating DNA synthesis: from recruiting to activating the MCM complex. J Cell Sci 114: 1447-1454

Masai H, Arai K (2002) Cdc7 kinase complex: a key regulator in the initiation of DNA replication. J Cell Physiol 190: 287-296

McGarry TJ, Kirschner MW (1998) Geminin, an inhibitor of DNA replication, is degraded during mitosis. Cell 93: 1043-1053

McPherson K, Steel CM, Dixon JM (2000) ABC of breast diseases. Breast cancer-epidemiology, risk factors, and genetics. Bmj 321: 624-628

Mendez J, Stillman B (2000) Chromatin association of human origin recognition complex, cdc6, and minichromosome maintenance proteins during the cell cycle: assembly of prereplication complexes in late mitosis. Mol Cell Biol 20: $8602-8612$

Meng MV, Grossfeld GD, Williams GH, Dilworth S, Stoeber K, Mulley TW, Weinberg V, Carroll PR, Tlsty TD (2001) Minichromosome maintenance protein 2 expression in prostate: characterization and association with outcome after therapy for cancer. Clin Cancer Res 7: 2712-2718

Mori I, Yang Q, Kakudo K (2002) Predictive and prognostic markers for invasive breast cancer. Pathol Int 52: 186-194
Nishitani H, Lygerou Z (2002) Control of DNA replication licensing in a cell cycle. Genes Cells 7: 523-534

Quinn LM, Herr A, McGarry TJ, Richardson H (2001) The Drosophila Geminin homolog: roles for Geminin in limiting DNA replication, in anaphase and in neurogenesis. Genes Dev 15: 2741-2754

Rampaul RS, Pinder SE, Elston CW, Ellis IO (2001) Prognostic and predictive factors in primary breast cancer and their role in patient management: The Nottingham Breast Team. Eur J Surg Oncol 27: $229-238$

Reya T, Morrison SJ, Clarke MF, Weissman IL (2001) Stem cells, cancer, and cancer stem cells. Nature 414: 105-111

Rodins K, Cheale M, Coleman N, Fox SB (2002) Minichromosome maintenance protein 2 expression in normal kidney and renal cell carcinomas: relationship to tumor dormancy and potential clinical utility. Clin Cancer Res 8: 1075-1081

Shreeram S, Blow JJ (2003) The role of the replication licensing system in cell proliferation and cancer. Prog Cell Cycle Res 5: 287-293

Shreeram S, Sparks A, Lane DP, Blow JJ (2002) Cell type-specific responses of human cells to inhibition of replication licensing. Oncogene 21: $6624-6632$

Stoeber K, Halsall I, Freeman A, Swinn R, Doble A, Morris L, Coleman N, Bullock N, Laskey RA, Hales CN, Williams GH (1999) Immunoassay for urothelial cancers that detects DNA replication protein $\mathrm{Mcm} 5$ in urine (letter). Lancet 354: 1524-1525

Stoeber K, Swinn R, Prevost AT, de Clive-Lowe P, Halsall I, Dilworth SM, Marr J, Turner WH, Bullock N, Doble A, Hales CN, Williams GH (2002) Diagnosis of genito-urinary tract cancer by detection of minichromosome maintenance 5 protein in urine sediments. J Natl Cancer Inst 94: $1071-1079$

Stoeber K, Tlsty TD, Happerfield L, Thomas GA, Romanov S, Bobrow L, Williams ED, Williams GH (2001) DNA replication licensing and human cell proliferation. J Cell Sci 114: $2027-2041$

Tada S, Li A, Maiorano D, Mechali M, Blow JJ (2001) Repression of origin assembly in metaphase depends on inhibition of RLF-B/Cdt1 by geminin. Nat Cell Biol 3: $107-113$

Wharton SB, Chan KK, Anderson JR, Stoeber K, Williams GH (2001) Replicative $\mathrm{Mcm} 2$ protein as a novel proliferation marker in oligodendrogliomas and its relationship to Ki67 labelling index, histological grade and prognosis. Neuropathol Appl Neurobiol 27: 305-313

Wharton SB, Hibberd S, Eward KL, Crimmins D, Jellinek DA, Levy D, Stoeber K, Williams GH (2004) DNA replication licensing and cell cycle kinetics of oligodendroglial tumours. Br J Cancer 91: 262-269

Williams G, Stoeber K (1999) Clinical applications of a novel mammalian cell-free DNA replication system. Br J Cancer 80(Suppl 1): 20-24

Williams GH, Romanowski P, Morris L, Madine M, Mills AD, Stoeber K, Marr J, Laskey RA, Coleman N (1998) Improved cervical smear assessment using antibodies against proteins that regulate DNA replication. Proc Natl Acad Sci USA 95: 14932-14937

Williams GH, Swinn R, Prevost AT, Clive-Lowe P, Halsall I, Going JJ, Hales CN, Stoeber K, Middleton SJ (2004) Diagnosis of oesophageal cancer by detection of minichromosome maintenance 5 protein in gastric aspirates. Br J Cancer 91: 714-719

Wohlschlegel JA, Dwyer BT, Dhar SK, Cvetic C, Walter JC, Dutta A (2000) Inhibition of eukaryotic DNA replication by geminin binding to Cdt1. Science 290: 2309-2312

Yoshida H, Akeho M, Yumoto T (1982) Giant cell tumor bone. Enzyme histochemical, biochemical and tissue culture studies. Virchows Arch (Pathol Anat) 395: 319-330

Yoshida K, Oyaizu N, Dutta A, Inoue I (2004) The destruction box of human Geminin is critical for proliferation and tumor growth in human colon cancer cells. Oncogene 23: 58-70 